but the present results show no differences here. Moreover, the over-all incidence of psychosis was the same in males as in females.

Many explanations could be put forward ${ }^{\star}$ to explain the disparity between these and previous results. An important one is certainly the difference in sampling. This study is free of all the biases to which a survey based on consecutive hospital admissions is liable. It is a great pity that we are not able to carry out epidemiological work of such a high standard in this country.

Several other aspects of the twins and their families are reported. In the discordant pairs, both $M Z$ and $D Z$, the schizophrenic twin was in childhood more submissive, reserved, lonely, obsessive, dependent, sensitive, and obedient. Birth order, birthweight, difficult birth, and physical strength in early childhood were not related to later psychosis; nor could any environmental factors be found to explain the discordance. All these findings agree with previous work.

The case histories of the schizophrenic $M Z$ twins are given in a second volume, though not, unfortunately, those of the twins suffering from reactive and manicdepressive psychoses. A tabulation of the main details of all the pairs at the end of the first volume would have been an enormous help to those who wish to rework the data, but tabulation is restricted to the age and diagnosis of the $M Z$ pairs. With the addition of birth order, sibship size, age at onset, age and manner of disappearance from observation, and a brief coding of family history, for $M Z$ and $\mathrm{DZ}$ pairs, the data would have been far more widely used and the addition would have been well worth the extra space. Consider, for instance, the invaluable appendices to Stenstedt's monograph on manic-depressive psychosis.

In summary, this investigation was carried out by a very able worker under relatively ideal epidemiological conditions. It is the most satisfactory twin study of psychosis published so far and deserves to be widely studied.

John PRICE

Cell Function, 2nd Edition. By L. L. Langley. (Pp. xiii +364 ; illustrated. 93s. 6d.) New York, London: Reinhold. 1968.

The scope of this book is well shown by the following justification: 'Our knowledge of intracellular activities has advanced so spectacularly that one can hardly be considered educated today if he does not have at least a nodding acquaintance with the processes by which cells replicate, produce energy, generate electricity and control

\footnotetext{
* See the discussion by J. Shields in the Proceedings of the Foundations' Fund for Psychiatry Conference on The Transmission of Schizophrenia, Puerto Rico, fune 1967. (Ed. S. S. Kety and D. Rosenthal) to be published as a supplement to the fournal of Psychiatric Research.
}

our growth and demise.' In presenting his material, the author has drawn heavily on review articles published in The Scientific American, of which he writes 'In my opinion these articles represent science writing at the very best ... and they are presented in a manner comprehensible to any educated person. For too long, science articles and books have been written in an esoteric jargon that may mask illiteracy and perhaps impress one's colleagues; but more often such jargon merely provides vivid evidence of muddled thinking.'

The author has succeeded in his aim of explaining clearly and briefly an astonishingly wide range of aspects of cellular biology. All terms are defined simply-no mean achievement when dealing with the physical chemistry of protoplasm and of the cell membrane; the basic principles and reactions of metabolism; the structure and function of lysosomes; with movement whether of muscle, of cilia, or of protoplasmic streaming; with reproduction and the biochemistry of inheritance. The problems of immunity, cancer, radiation, and ageing are touched on briefly and there is even a very welcome chapter on membrane and action potentials. The text is superbly illustrated and carries a good index. The Scientific American style helps in making this book fascinating as well as useful, but it also involves some over-simplification and occasionally the journalistic style becomes irritatingly irrelevant-a minor flaw in an outstandingly successful presentation of a complex subject.

Joseph Chayen

The Ultrastructure of the Animal Cell. By L. T Threadgold. (Pp. xxiii and 313, illustrated. 100s.) Oxford: Pergamon Press.

This book aims at discussing in detail the ultrastructure of animal cells and at relating structure to function. It begins with a somewhat inadequate introduction to electron microscopy. The main body of the book is divided into two parts, one on 'The Interphase Cell' and the other on 'The Dividing Cell'. The value of this book is that it is lavishly illustrated by electron micrographs, mostly borrowed from established experts, to show the structure of each component of animal cells; these are taken from a wide range of animals. It also carries many line drawings to show how the pictures have been interpreted.

The writing is not always clear, and is not helped by the use of unusual technical terms. Probably, however, the real difficulty derives from the fact that the author has tried to do too much. As he himself says 'the accumulated observations on cell ultrastructure now form a vast pool of information, which is rapidly increasing. Expertise over the whole spectrum of this knowledge is beyond the scope of one man.' This seems to apply even more to any attempt to relate function to structure as well as to ultrastructure. 
The text deliberately is not supported by concrete evidence, or references to detailed studies, so that the treatment of complex problems in cell structure and function becomes too superficial to be as useful as it could be.

JOSEPH ChAYEN cessors. It will be indispensable to immunologists and geneticists interested in the control and variation of protein synthesis. Despite the rapidity of progress in the biological sciences, its contents will remain essential reading.

L. E. GLYNN

\section{Surveys and Symposia}

Cold Spring Harbor Symposia on Quantitative Biology. Vol. XXXII. Antibodies. Edited by Leonora Frisch. (Pp. xix +619 ; illustrated + tables. \$20.00.) New York: Cold Spring Harbor Laboratory of Quantitative Biology. 1968.

The nature of immunological specificity has been and still is the central problem of immunology, and now that direct template theories of antibody synthesis are no longer tenable interest has focused upon the primary structure of antibodies, i.e. the amino acid sequence of their constituent polypeptide chains. Since, according to the current teaching of molecular biology, this sequence is determined by the base sequence of the corresponding gene, and since the number of specifically distinct antibodies capable of synthesis by a single individual may be several thousands or even tens of thousands, it must be conceded that this enormous number of genes coding for a single class of proteins is available in every normal antibody-producing animal. The manner in which this phenomenal genetic potentiality is achieved is of fundamental interest to both immunologists and geneticists, and formed the central theme of the symposium on antibodies, being the thirty-second symposium on quantitative biology held at Cold Spring Harbor in June 1967.

The majority of the participants support some form of clonal selection by antigen, as first put forward by Burnet. This requires a truly remarkable degree of somatic mutation to provide the necessary variety of stem cells each capable of reacting to a different antigenic pattern. Of the several hypotheses discussed, the one presented by Smithies seems to cover the widest range of observed facts with the minimum of assumptions. It postulates the control of the variable part of the antibody light chain by a gene pair consisting of a master gene and a scrambler gene. Crossing-over between these two genes can then give rise to the variability in amino acid sequence as observed in the structure of these peptide chains.

A further aspect of immunology of especial interest to geneticists is the large number of genetically determined allotypes in which the immunoglobulins appear. These allotypes, usually dependent upon single amino acid substitutions, affect both the heavy and light chains of the whole immunoglobulin molecule. The subject received detailed attention by many of the speakers.

The standard of the communications at this symposium achieved the high level established by its prede-
Histo- und Zytogenese der sich entwickelnden Retina: Eine elektronenmikroskopische Studie. By Karl Meller. (Pp. viii + 77; 47 figures. DM.21.) Stuttgart: Gustav Fischer Verlag. 1968.

This small and carefully detailed monograph deals with the histogenesis and cytogenesis of the developing retina of the chick. It follows the differentiation of the primitive ectodermal cells (the germinal cells) into the many cell types that comprise the adult eye. Special emphasis is given to the Müller cells-the neuroglia of the retina-but every cell type is described both as to its structure and its origin. The electron micrographs are of a high standard and are clearly labelled. The ultrastructure is frequently clarified by comparison with retina prepared by the conventional Golgi method. This very neat monograph is completed by a useful bibliography.

Kraniofaziale Dysplasien und Störungen der Zahnentwicklung Experimentelle und vergleichende Untersuchungen. By W. Ritter. (Pp. $x i+112$; illustrated + tables. $D M$ 35.) Stuttgart: Gustav Fischer Verlag. 1968.

This is a detailed account of the malformations seen in 2055 newborn mice belonging to 4 different strains and derived from litters exposed to a single dose of radiation to the head-anlage at various successive states of pregnancy. Special attention was paid to the anomalies of the lower jaw and teeth, as earlier teratological investigations appeared to stress craniofacial rather than mandibular defects. Radiation was found most effective when applied on the 7th or 8th day of embryonic life. The genetic basis of these induced anomalies was shown by the fact that there were striking differences in the frequency of $x$-ray induced malformations in the 4 strains studied. In one strain in which mandibular hypoplasia occurred spontaneously in some $5 \%$ of offspring, the incidence rose to $43 \%$ after irradiation. The deformities observed fell into two main types, one being arrhinencephaly-cyclopia and the other craniofacial otocephalic. When deformities of tooth germ occurred, the whole of the germ tended to be involved, probably because of spatial relationship.

There is a useful survey of the literature and a discussion on analogous human anomalies which show a rather less complete group of variations than is seen in the experimental material. 